\title{
Humanização do Cuidado da UTI Neonatal ${ }^{1}$
}

\section{Humanization in Neonatal I CU Care}

\section{Humanización del Cuidado en la UTI Neonatal}

\author{
Altamira Pereira da Silva Reichert ', Rilávia Nayara Paiva Lins ", Neusa Collet "'
}

\begin{abstract}
RESUMO
Pesquisa de natureza qualitativa do tipo bibliográfica cujo objetivo foi identificar ações de enfermagem descritas na literatura que contribuem para a humanização da assistência na Unidade de Terapia Intensiva Neonatal (UTIN). A busca do material foi realizada em bancos de dados informatizados e em livros e periódicos da área. Os textos foram selecionados a partir do conteúdo dos resumos e lidos várias vezes a fim de construir os núcleos de sentido. Os resultados demonstram que as ações de enfermagem com vistas à humanização em UTIN devem pautar-se na construção do cuidado singular, na integralidade e no respeito à vida.
\end{abstract}

Palavras chave: Humanização da assistência; Recém-nascido; Enfermagem.

\section{ABSTRACT}

This study is a qualitative and bibliographical research which objective is identifying the nursing actions as described in nursing literature and that contributes to the humanization in Newborn Intensive Care Unities (NICU). The data was collected in informatized data banks, books and magazines. The texts were all selected up in order to make sense in the subject. The results show that the nursing actions in NICU must have as their target the singular care, integrality and the respect for life.

Key-Words: Humanization of assistance; Newborn; Nursing.

\section{RESUMEN}

Investigación de naturaleza cualitativa de tipo bibliográfico cuyo objetivo fue identificar acciones de enfermería descritas en la literatura que contribuyen a la humanización de la asistencia en la Unidad de Terapia Intensiva Neonatal (UTIN). La revisión fue realizada en bancos de datos informatizados y en libros y revistas especializadas del área. Los textos fueron seleccionados a partir del contenido de los resúmenes y leídos varias veces a fin de conformar los núcleos de sentido. Los resultados demuestran que las acciones de enfermería con vistas a la humanización en UTIN deben sustentarse en la aplicación del cuidado singular, en la integralidad y en el respeto a la vida.

Palabras clave: Humanización de la atención; Recién nacido; Enfermería.

\footnotetext{
${ }^{1}$ Parte do Trabalho de Conclusão do Curso de Graduação em Enfermagem da Universidade Federal da Paraíba.

'Enfermeira. Mestre em Enfermagem em Saúde Pública pela UFPB. Doutoranda no Programa de Pós-Graduação em Saúde da Criança e do Adolescente da Universidade Federal de Pernambuco - UFPE. Docente da disciplina Enfermagem em Clínica Pediátrica do Curso de Graduação em Enfermagem da Universidade Federal da Paraíba UFPB. E-mail: altreichert@uol.com.br

"Enfermeira. Doutora em Enfermagem pela EERP-USP, Docente da disciplina Enfermagem em Clínica Pediátrica do Curso de Graduação em Enfermagem da Universidade Federal da Paraíba - UFPB, docente do Programa de PósGraduação em enfermagem da UFPB. E-mail: ncollet@terra.com.br

III Enfermeira. Graduada no Curso de Enfermagem da Universidade Federal da Paraíba - UFPB. E-mail: altreichert@uol.com.br
} 


\section{NTRODUÇÃO}

A criança é um ser único, pleno de potencialidades, vivenciando durante toda sua vida intra-uterina e no momento do nascimento, uma série de transformações que serão decisivas no seu crescimento e desenvolvimento saudáveis ${ }^{(1)}$.

O ambiente da Unidade de Terapia Intensiva Neonatal (UTIN) propicia uma experiência ao recém-nascido bastante diferente daquela do ambiente uterino, uma vez que este é o ideal para o crescimento e desenvolvimento fetal, pois possui características distintas, como temperatura agradável e constante, macicez, aconchego, e os sons extra-uterinos são filtrados e diminuídos.

Nesse contexto, "o surgimento das CTI trouxe um universo mais amplo à assistência aos recém-nascidos, permitindo a sobrevivência de bebês que teriam poucas chances há alguns anos"(2).

Apesar da importância da UTIN para oS neonatos doentes, contraditoriamente, essa unidade que deveria zelar pelo bem-estar da criança em todos os seus aspectos, é por excelência um ambiente nervoso, impessoal e até temeroso para aqueles que não estão adaptados às suas rotinas. Tal ambiente é repleto de luzes fortes e constantes, barulho, mudanças de temperatura, interrupção do ciclo do sono, visto que são necessárias repetidas avaliações e procedimentos, acarretando, muitas vezes, desconforto e dor.

A fim de dar conta da complexidade que é assistir o RN em uma UTIN, enfatizamos a importância do envolvimento da equipe de enfermagem na assistência ao binômio mãefilho ressaltando a necessidade de humanizar essa assistência, facilitando a interação entre equipe profissional-RN-mãe. Esse cuidado proporciona o crescimento e desenvolvimento e recuperação do $\mathrm{RN}$ de forma satisfatória e contribui para minimizar os efeitos nocivos provocados pela hospitalização, tornando os pais elementos ativos dentro do processo de hospitalização, além de contribuir para uma boa qualidade de sobrevida do bebê(3).

Assim, nesta pesquisa, propomo-nos trazer ao debate uma reflexão acerca das ações de humanização do cuidado desenvolvidas em UTIN pela enfermagem. Portanto, o objetivo deste trabalho é identificar na literatura ações de enfermagem que contribuem para a humanização da assistência na Unidade de Terapia Intensiva Neonatal.

\section{METODOLOGI A}

Para a realização desta pesquisa optamos pela abordagem de natureza qualitativa, uma vez que esta permite entrar em profundidade na essência do tema proposto. A pesquisa qualitativa permite compreender as representações de um determinado grupo e entender o valor cultural que estes atribuem a determinados temas. $O$ desenho escolhido para a mesma foi de um estudo bibliográfico, pois foi desenvolvido com base em material já elaborado, constituída de livros e artigos científicos $^{(4)}$.

Ao delimitarmos o tema da pesquisa, realizamos um estudo exploratório a fim de nos aproximarmos dos conceitos que envolvem a humanização na UTIN, buscando trabalhos de natureza teórica capazes de proporcionar explicações a respeito do tema proposto, bem como de pesquisas que abordavam o assunto. 
Para tanto, realizamos um levantamento bibliográfico sobre o tema nos bancos de dados informatizados MEDLINE, LILACS, CINAHL, SciELO e consulta manual em periódicos da área. A busca dos artigos deu-se por meio do uso das palavras-chave, a saber, prematuridade, UTIN, neonatologia, enfermagem neonatológica, humanização da assistência, dentre outras. Realizamos pesquisa na literatura nacional publicada no período entre 1996 a 2006, procurando diversificar os periódicos para alcançar um número maior de publicações que abordassem o tema em questão. De posse do material realizamos uma leitura do tipo exploratória que tem por objetivo verificar, em que medida o obra consultada interessa à pesquisa. Nesse momento, obtivemos maior familiaridade com o tema da investigação. A leitura exploratória é feita mediante o exame da folha de rosto ou resumo, dos índices da bibliografia e das notas de rodapé. Também faz parte deste tipo de leitura o estudo da introdução, do prefácio, livros e resumos de artigos. Com esses elementos, é possível ter uma visão global do texto, bem como sua utilidade para a pesquisa $^{(5)}$.

A próxima etapa constituiu-se da determinação do material de interesse à pesquisa. Nesse momento, realizamos a leitura seletiva a qual é mais profunda que a exploratória, que ainda não é definitiva, pois possibilita a retomada do mesmo material com propósitos diferentes ${ }^{(5)}$.

Posteriormente, procedemos à leitura do tipo analítica que é feita com base nos textos selecionados. Essa etapa tem por finalidade ordenar e sumarizar as informações contidas nas fontes, de forma que estas possibilitem a obtenção de respostas ao problema da pesquisa ${ }^{(5)}$. Assim, os textos foram lidos várias vezes a fim de identificarmos sua relação com o objeto desta pesquisa, constituindo-se como critério de inclusão dos textos aqueles que abordaram a temática em estudo.

Por fim, realizamos a leitura interpretativa que tem por objetivo relacionar o que o autor afirma como problema para o qual se propõe uma solução. Dessa forma, foi possível elencar o material, extrair dos textos temas de interesse nesta pesquisa e interpretá-los a partir do objetivo proposto.

Assim, a partir das leituras do material selecionado, surgiram os seguintes temas: o ambiente da UTIN e a humanização do cuidado; o vínculo afetivo entre pais/família e filho; a enfermagem como agente facilitador no processo de humanização, conforme apresentados a seguir.

\section{RESULTADOS E DISCUSSÃO}

Os trabalhos selecionados e analisados na presente pesquisa reuniram um total de 17 documentos, sendo 11 artigos, 03 livros e 02 dissertações e 01 monografia, conforme pode ser observado no Quadro 1. 
Quadro 1: Trabalhos pesquisados segundo tipo do documento, autores, ano da publicação e título.

\begin{tabular}{|c|c|c|c|}
\hline $\begin{array}{c}\text { PERIÓDICOS/ NÚMERO DE } \\
\text { ARTIGOS }\end{array}$ & AUTORES & ANO & TítULO \\
\hline \multirow[t]{2}{*}{ Revista Eletrônica de Enfermagem } & $\begin{array}{l}\text { Fernandes; Andraus; } \\
\text { Munari }\end{array}$ & 2006 & $\begin{array}{l}\text { O aprendizado do cuidar da família da } \\
\text { criança hospitalizada por meio de } \\
\text { atividades grupais. }\end{array}$ \\
\hline & $\begin{array}{l}\text { Pinho; Siqueira; } \\
\text { Pinho }\end{array}$ & 2006 & $\begin{array}{l}\text { As percepções do enfermeiro acerca da } \\
\text { integralidade da assistência. }\end{array}$ \\
\hline $\begin{array}{l}\text { Revista Mineira de Enfermagem - } \\
\text { REME } \\
01 \text { trabalho }\end{array}$ & Araújo & 2005 & $\begin{array}{l}\text { Trabalho no centro de terapia intensiva: } \\
\text { perspectivas da equipe de enfermagem. }\end{array}$ \\
\hline $\begin{array}{l}\text { Revista de Ciências e Saúde } \\
\text { Coletiva }\end{array}$ & $\begin{array}{l}\text { Lamego; Deslandes; } \\
\text { Moreira }\end{array}$ & 2005 & $\begin{array}{l}\text { Desafios para a humanização do cuidado } \\
\text { em uma Unidade de Terapia Intensiva } \\
\text { Neonatal cirúrgica. }\end{array}$ \\
\hline $\begin{array}{l}\text { Revista Latino-Americana de } \\
\text { Enfermagem }\end{array}$ & $\begin{array}{l}\text { Rossato-Abéde; } \\
\text { Ângelo }\end{array}$ & 2002 & $\begin{array}{l}\text { Crenças determinantes na interação da } \\
\text { enfermeira acerca da presença dos pais em } \\
\text { unidades neonatais de alto risco. }\end{array}$ \\
\hline $\begin{array}{l}\text { Revista Médica do Hospital São } \\
\text { Vicente de Paulo }\end{array}$ & Carvalho & 2002 & $\begin{array}{l}\text { A enfermagem na promoção da presença } \\
\text { dos pais-familiares em CTI } \\
\text { pediátrica/neonatal. }\end{array}$ \\
\hline Revista Paulista de Enfermagem & Scochi et al. & 2001 & $\begin{array}{l}\text { Cuidado individualizado ao pequeno } \\
\text { prematuro: o ambiente sensorial em } \\
\text { unidade de terapia intensiva neonatal. }\end{array}$ \\
\hline Revista Saúde em Foco & Ratto & 2001 & $\begin{array}{l}\text { É possível humanizar a assistência ao } \\
\text { parto? Avaliação de dois anos da } \\
\text { maternidade Leila Diniz }\end{array}$ \\
\hline $\begin{array}{l}\text { Nursing - Revista Técnica de } \\
\text { Enfermagem }\end{array}$ & Nascimento; Martins & 2000 & $\begin{array}{l}\text { Reflexões acerca do trabalho da } \\
\text { enfermagem em UTI e a relação deste com } \\
\text { o indivíduo hospitalizado e sua família. }\end{array}$ \\
\hline Jornal de Pediatria & $\begin{array}{l}\text { Lamy; Gomes; } \\
\text { Carvalho }\end{array}$ & 1997 & $\begin{array}{l}\text { A percepção dos pais sobre a internação de } \\
\text { seus filhos em Unidade de Terapia } \\
\text { Intensiva Neonatal. }\end{array}$ \\
\hline Revista Pediatria Moderna & Ferraz; Chaves & 1996 & Bebês prematuros: aspectos emocionais. \\
\hline LIVROS & AUTORES & ANO & TíTULO DO CAPÍTULO \\
\hline $\begin{array}{l}\text { Quando a vida começa diferente: } \\
\text { o bebê e sua família na UTI } \\
\text { neonatal }\end{array}$ & $\begin{array}{l}\text { Moreira; Rodrigues; } \\
\text { Braga; Morsch }\end{array}$ & 2003 & Conhecendo uma UTI neonatal \\
\hline $\begin{array}{l}\text { Desenvolvimento gerencial de } \\
\text { Unidades Básicas de Saúde do } \\
\text { Sistema Único de Saúde }\end{array}$ & Nogueira & 1997 & O trabalho em serviços de saúde \\
\hline Experiência de ser mãe de recém- & Reichert; Costa & 2000 & \\
\hline
\end{tabular}


Reichert APS, Lins RNP, Collet N. Humanização do Cuidado da UTI Neonatal. Revista Eletrônica de Enfermagem [serial on line] 2007 Jan-Abr; 9(1): 200-213. Available from: URL: http://www.fen.ufg.br/revista/v9/n1/v9nla16.htm

\begin{tabular}{|l|l|l|l|}
\hline nascido prematuro & \multicolumn{1}{|c|}{ AUTORES } & ANO & \multicolumn{1}{|c|}{ Tí TULO } \\
\hline \multicolumn{1}{|c|}{ DI SSERTAÇÃO } & Moreira & 2001 & $\begin{array}{l}\text { Estressores em mães de recém-nascidos de } \\
\text { alto risco: sistematização da assistência de } \\
\text { enfermagem }\end{array}$ \\
\hline Mestrado & Oliveira & 1998 & $\begin{array}{l}\text { Cuidando-aprendendo enfermagem com } \\
\text { amor: uma experiência dialógica com } \\
\text { mães/recém-nascidos pré-termo }\end{array}$ \\
\hline MONOGRAFI A & Lima & 2004 & $\begin{array}{l}\text { Humanização na unidade de terapia } \\
\text { intensiva pediátrica: discurso de } \\
\text { enfermeiras }\end{array}$ \\
\hline
\end{tabular}

Na seqüência passamos a apresentar e discutir os temas que surgiram da análise.

\section{O ambiente da UTI N e a humanização do} cuidado

A UTIN é um ambiente hospitalar onde são utilizados técnicas e procedimentos sofisticados, que podem propiciar condições para a reversão dos distúrbios que colocam em risco a vida dos bebês de alto risco.

A hospitalização em UTIN introduz o bebê em um ambiente inóspito, onde há exposição intensa a estímulos nociceptívos, como o estresse e a dor que são freqüentes ${ }^{(6)}$. Ruídos, luz intensa e contínua, bem como procedimentos clínicos invasivos e dolorosos são constantes nessa rotina.

o local é, em geral, repleto de equipamentos e rico em tecnologia. Os RNs de risco convivem com inúmeras terapias agressivas, estressantes e dolorosas, advindas dos avanços tecnológicos da assistência, as quais produzem desorganização fisiológica e comportamental nos neonatos, refletindo negativamente nos cuidados aos mesmos.

É contínuo o movimento de admissões e intervenções no setor. No meio destas atividades encontra-se o bebê, o qual necessita de cuidados especiais, a exemplo de incubadoras para mantê-lo aquecido, de oxigênio para evitar asfixia, de sondas ou cateteres para alimentá-lo.

É inquestionável que a evolução da tecnologia modificou o prognóstico e a sobrevida dos bebês de alto risco. No entanto, a fragilidade da pele, bem como a presença de tubos e sondas são causas de sofrimento, visto que os mesmos não estão preparados para tantos estímulos que Ihes são estranhos e assustadores, considerando que antes viviam em um ambiente protegido pelo líquido amniótico, ouviam os batimentos cardíacos da sua mãe, e o som da voz dela.

Para os pais, a UTIN é um ambiente de esperança e de medo. Esperança por saber que este é um local preparado para atender melhor - seu filho e aumentar as chances de sobrevida. Medo, por saber dos riscos inerentes aos pacientes que vão para tal ambiente, e ainda, sentimentos de frustração, por não estarem, em geral, preparados para esta separação.

A equipe de profissionais que trabalha na UTIN, em especial a enfermagem, também é submetida a vários estímulos estressantes. O ritmo de trabalho é intenso e exaustivo. Há 
uma exigência crescente de eficiência e atualização de conhecimentos. É necessário ter habilidade de relacionamento, bem como segurança na execução de técnicas e manipulação de máquinas e equipamentos complexos.

Diante do exposto, é lícito afirmar que esses fatores têm acarretado conseqüências aos bebês e seus familiares e à equipe de enfermagem das UTINs. Apesar desse cenário que às vezes dificulta 0 atendimento humanizado por parte de alguns profissionais de saúde às crianças hospitalizadas, vem sendo observada uma mudança de consciência e comportamento em alguns profissionais quanto à importância de prestar uma assistência mais humanizada(7).

Assim, é oportuno repensar as ações em saúde neste âmbito, visando a humanização da assistência em UTINs pautada no atendimento das necessidades de todos os agentes envolvidos nesse processo.

Para iniciar a discussão do tema proposto, surge nosso primeiro questionamento: qual o significado da humanização da assistência em saúde e no que consiste esse processo?

A palavra humanização pode ser entendida como a maneira de ver e considerar o ser humano a partir de uma visão global, buscando superar a fragmentação da assistência. Um dos aspectos que envolvem uma prática dessa natureza está relacionado ao modo como lidamos com o outro. Uma das características do processo de trabalho em saúde é que o mesmo "se funda numa interrelação pessoal muito intensa"(8). Assim, essa característica implica em fazermos a diferença no modo como lidamos com outro, tratando-o com dignidade e respeito, valorizando seus medos, pensamentos, sentimentos, valores e crenças, estabelecendo momento de fala e de escuta.

A humanização "não pode ser pensada sem re-pensarmos paralelamente a questão da educação como prioridade numa agenda de mudanças, pois o que percebemos hoje é que a educação no campo da saúde encontra-se reduzida à informatização e a instrumentalização tecnológica em detrimento dos aspectos éticos e humanos que estas tecnologias implicam"(9).

Mais do que isso "humanizar não é uma técnica ou artifício, é um processo vivencial que permeia toda a atividade das pessoas que assistem o paciente, procurando realizar e oferecer o tratamento que ele merece como pessoa humana, dentro das circunstâncias peculiares que se encontra em cada momento no hospital”(10).

$E$, nesse ambiente, a humanização representa um conjunto de iniciativas que visa à produção de cuidados em saúde capaz de conciliar a melhor tecnologia disponível com promoção de acolhimento e respeito ético e cultural ao paciente, de espaços de trabalho favoráveis ao bom exercício de saúde e usuários $^{(11)}$.

Já na humanização do cuidado Neonatal, o Ministério da Saúde preconiza várias ações, as quais estão voltadas para o respeito às individualidades, à garantia da tecnologia que permita a segurança do recém-nato e o acolhimento ao bebê e sua família, com ênfase no cuidado voltado para o desenvolvimento e psiquismo, buscando facilitar o vínculo paisbebê durante sua permanência no hospital e após a alta. 
Reichert APS, Lins RNP, Collet N. Humanização do Cuidado da UTI Neonatal. Revista Eletrônica de Enfermagem [serial on line] 2007 Jan-Abr; 9(1): 200-213. Available from: URL: http://www.fen.ufg. br/revista/v9/n1/v9nla16.htm

A partir da literatura pesquisada, identificamos ser de fundamental importância à equipe de enfermagem que atua em UTIN a busca de medidas que minimizem o sofrimento e a dor do bebê e sua família. Nesse sentido, devemos enfatizar a humanização do processo de assistir por meio de reconhecimento e tratamento adequado dos agentes estressores ao binômio bebê-família.

Dessa forma, é necessário investir na formação e sensibilização dos profissionais de saúde das UTINs, promovendo não somente a capacitação técnica, mas, também, sensibilizando-os para que planejam a assistência pautada nos fundamentos da humanização e da integralidade do cuidado, a fim de proporcionar ao bebê e sua família um ambiente tranqüilo e acolhedor, apesar da situação de hospitalização vivenciada.

\section{O vínculo afetivo entre pais/ família e filho}

O nascimento de um bebê idealizado pelos pais durante a gestação é um momento de muitas modificações e realizações. Com as primeiras manifestações de vida em seu útero, a mulher começa a imaginar como será o seu bebê, atribuindo-Ihe características pessoais, passando a desenvolver, a partir deste momento, sentimentos de apego que influenciarão por toda a vida da criança.

O apego é o laço afetivo que os pais estabelecem com o bebê, essencial para a sua sobrevivência e desenvolvimento, podendo ser expresso por meio dos sentidos. Quando estabelecidos, prepara-os para a separação no momento do parto, mas nem sempre esta separação ocorre de forma favorável ${ }^{(7)}$.

A separação do bebê de seus pais logo após o nascimento devido uma patologia, gera reações diferentes e imprevisíveis, especialmente quando esse bebê é internado em uma UTIN. Tal experiência representa aos pais um momento conflituoso em suas vidas, gerando alterações no seu cotidiano, trazendo sentimentos de angústia, dúvidas, medo do prognóstico e dificuldade na aceitação da separação e condição do filho.

O ambiente da UTIN que é tão familiar para os profissionais de saúde, para os pais, é percebido como assustador, razão pela qual eles têm dificuldade de reconhecer $\mathrm{o}$ bebê como seu. Essa dificuldade no reconhecimento ocorre porque, durante a gravidez, os pais sonham com um bebê imaginário saudável, perfeito e lindo. Então, quando do nascimento, há um contraste muito grande entre a criança imaginária e aquela que eles visualizam ${ }^{(12)}$.

A situação crítica vivenciada pelo recémnascido de risco é geradora de grande estresse na família, especialmente nos pais, sendo intensificado pelo próprio ambiente físico da UTIN, dotado de equipamentos, pela tecnologia utilizada, pela insuficiência de informações com relação à utilização dessas ferramentas de cuidado.

A internação em uma UTIN promove desequilíbrio emocional do bebê e de seus pais, constituindo-se em uma situação de estresse. No momento da internação, os pais podem se desestruturar e criar fantasias ameaçadoras em torno das diferentes situações que envolvem o termo UTI. Geralmente isso leva a uma desorganização emocional dos mesmos, tornando-os ansiosos e impacientes.

Essa desorganização emocional gera conflitos, ansiedade e agrava a sensação de culpa dos pais dificultando sua compreensão de que é importante para o seu bebê que eles 
Reichert APS, Lins RNP, Collet N. Humanização do Cuidado da UTI Neonatal. Revista Eletrônica de Enfermagem [serial on line] 2007 Jan-Abr; 9(1): 200-213. Available from: URL: http://www.fen.ufg.br/revista/v9/n1/v9nla16.htm

estejam presentes no processo de hospitalização. É válido ressaltar que a equipe de saúde que atua na UTIN deve considerar esses sentimentos no processo cotidiano de humanizar a assistência, pois os pais encontram-se apreensivos quanto à sobrevivência do bebê durante a hospitalização.

A primeira visita a UTIN pode ser deprimente para os pais. O recém-nascido tem, com freqüência, pelo menos uma infusão venosa, fios ligados para monitorização, sonda endotraqueal acoplada a um respirador e, na maioria das vezes, permanece confinado em incubadoras. Devido a isso, os pais necessitam de apoio médico e de enfermagem e uma orientação realista dos prognósticos a fim de compreender a doença da criança e o motivo de toda a aparelhagem para os cuidados recebidos $^{(7)}$.

A família vive uma tensão entre a aproximação e o distanciamento da criança devido à doença, à possibilidade de terminalidade, ao estar no mundo da UTIN com suas normas e rotinas, ao relacionamento com a equipe de saúde, aos conflitos familiares e à dificuldade de diferentes ordens para estar com seu filho.

Além disso, os pais experimentam a interrupção de suas atividades normais e das responsabilidades parentais. O estresse aumenta quando os pais percebem que a informação sobre a situação de saúde do filho é incompleta, conflitiva ou de difícil compreensão(2).

O estabelecimento e manutenção do vínculo durante o período de hospitalização é fundamental para o despertar do cuidado da família para com o bebê, como também, para acelerar o processo de recuperação da saúde deste. O contato íntimo dos pais com o bebê e o apego dos mesmos, exerce profundos efeitos no futuro crescimento e desenvolvimento do filho. Esse apego não pode ser visto somente como manifestação simples e rápida, mas como o início de um processo de experiências com o neonato bastante complexo.

A recuperação do bebê não depende unicamente dos cuidados médicos e de enfermagem, mas também dos cuidados e do carinho que possa vir a receber de seus pais $^{(13)}$.

Um ponto importante a ser considerado no tratamento do $\mathrm{RN}$ de risco é reduzir a ansiedade dos pais por meio do oferecimento de apoio, para ajudá-los na expressão de seus sentimentos. Se o pai ou a mãe experimenta um relacionamento positivo com um profissional no hospital, seu nível de ansiedade diminui e sua percepção da situação torna-se mais acurada(12).

Diante do exposto, a enfermagem deverá se fazer sempre presente, interagindo cotidianamente com o RN e familiares, compartilhando percepções, crenças e valores, auxiliando na reorganização dos pais e familiares, na sua adaptação em relação à situação vivenciada e ao ambiente do hospital, promovendo, assim, o desenvolvimento do apego dos pais/família com o bebê, sendo este de vital importância para um crescimento e desenvolvimento saudável da criança.

\section{A enfermagem como agente facilitador no processo de humanização}

A UTIN é, por excelência, o ambiente destinado ao atendimento de bebês de alto risco e, para tanto, exige de toda a equipe um 
preparo que sustente a complexidade das atividades desenvolvidas.

O conhecimento científico e a habilidade técnica são características imprescindíveis para o rigoroso controle das funções vitais na tentativa de reduzir a mortalidade e de garantir a sobrevivência dos RNs de risco. Assim, destacamos a importância do acompanhamento e da atualização dos avanços terapêuticos e tecnológicos nessa área.

Nesse processo, e no mesmo patamar de importância, colocamos a crucial necessidade em compreender os fatores que produzem estresse na UTIN a fim de elaborarmos um planejamento das intervenções que o minimizem ao máximo. São muitos os fatores considerados como causadores de estresse para os bebês, família e equipe, em especial, a de enfermagem.

No tocante à equipe de enfermagem, essa assume um leque de atribuições, capacidades e responsabilidades que são essenciais para avaliar, entender e apoiar com segurança o RN e a sua família durante esse tempo crítico $^{(3)}$.

É inquestionável que a atuação no âmbito da recuperação física do bebê na UTIN é prioridade, mas existe a consciência da necessidade de serem utilizados meios para minimizar o estresse em todo o seu contexto. Com isso, medidas devem ser adotadas de acordo com a realidade e possibilidade de cada serviço, para diminuir os efeitos negativos e/ou problemas psicoemocionais, comportamentais e motores, desencadeados pela doença e/ou permanência do bebê na UTIN.

Pelo exposto, compreendemos que a enfermagem tem papel relevante na manutenção das condições da vitalidade dos
RNs de risco, devendo fundamentar suas ações em conhecimentos científicos. Cabe ao enfermeiro da UTIN organizar o ambiente, planejar e executar os cuidados de enfermagem de acordo com a necessidade individualizada e resposta de cada criança, exercendo assim, uma assistência integral, de qualidade e humanizada ${ }^{(14)}$.

A capacitação dos profissionais de enfermagem para apreender as necessidades singulares de cada bebê é de grande importância para que os procedimentos e cuidados de rotina, dolorosos e invasivos, sejam empregados de forma individualizada e singular. Um dos primeiros passos nesse sentido é a observação acurada das respostas comportamentais e fisiológicas do bebê, visando à diminuição do estresse e da dor, contribuindo para o seu conforto, segurança e desenvolvimento.

Para que a assistência de enfermagem ao RN seja de qualidade, é fundamental atender às necessidades de repouso, calor, nutrição, higiene, observação e atendimento contínuo aos bebês ${ }^{(3)}$. A autora destaca que a observação rigorosa do comportamento da criança deve ser feita antes dela ser submetida a uma manipulação, durante os cuidados rotineiros e depois da execução dos mesmos, com a finalidade de identificar sinais de dificuldade de adaptação do bebê ao ambiente extra-uterino. Porém, vale ressaltar que não deve se deter apenas ao atendimento das necessidades biológicas do RN, mas envolver suas necessidades emocionais, apreendendo-o de forma holística.

Nesse contexto, é imperativo ressaltar a importância da atenção e do cuidado aos familiares nesse processo, em particular aos 
pais. Atualmente, observamos que a atenção aos pais, muitas vezes, limita-se a informações voltadas a questionamentos sobre a rotina hospitalar e sobre a situação do bebê, não havendo preocupação, na maioria dos casos, com os aspectos emocionais desses familiares $^{(15)}$.

Autores afirmam que as características peculiares desse papel incluem a habilidade de reconhecer e conviver com a família na situação de doença, incluindo-a no planejamento dos cuidados da criança, bem como, respeitando suas decisões em relação ao tratamento(16). Além disso, acreditamos que, ao valorizar a presença da família, sobretudo dos pais, durante o tratamento da criança, o enfermeiro e toda sua equipe desempenham um papel singular no cuidado aos recémnascidos.

Entretanto, podemos observar ainda que, na prática clínica, o desempenho do papel da enfermagem junto aos pacientes nem sempre revela ações de apoio à interação pais/recémnascidos, mas se mostram centrados nos aspectos técnico-biológicos, o que se constitui em fonte geradora de conflito, na medida em que tal situação reflete contradição entre a formação acadêmica e o exercício profissional $^{(14)}$.

Ainda neste contexto, identificamos que a literatura aponta que as condições insatisfatórias de trabalho relacionadas à precariedade de recursos humanos, acarretam sobrecarga emocional e de trabalho, contribuindo para que a assistência direta ao paciente não seja assumida como prioritária pelo enfermeiro. Diante das ansiedades que envolvem o trabalho na UTIN, a equipe de enfermagem utiliza mecanismos defensivos, como o distanciamento do paciente, negando, assim, os aspectos psicológicos dos mesmos e seus próprios sentimentos e desejos ${ }^{(14)}$.

Associado a isso, está o fato de que, em geral, a fadiga pelo ritmo de trabalho excessivo; lidar com questões de vida e morte continuamente; questões éticas que impõem decisões freqüentes e difíceis; alto grau de exigência dos demais profissionais do hospital, da família dos pacientes, e dos próprios colegas de equipe, podem acarretar desestruturação emocional.

Todos estes fatores fazem com que a equipe de enfermagem se esqueça de visualizar o ser humano que está à sua frente. Assim, torna-se difícil implementar a essência do aspecto humano relacionado ao cuidado de enfermagem.

O preparo dos pais para verem seu bebê pela primeira vez constitui uma responsabilidade da enfermagem. Antes da primeira visita os pais ou outros familiares devem ser preparados quanto ao aspecto da criança, o equipamento que está conectado ao mesmo e alguma informação acerca da atmosfera geral da unidade.

É importante que os profissionais de enfermagem, implementem suas ações no fortalecimento de relações interpessoais que envolvam a criança e seus pais, possibilitando reflexões e fornecendo apoio necessário acerca de seus conhecimentos, ansiedades e expectativas. Tal conduta é prioritária, em se tratando de UTIN, pois neste setor a capacidade técnica é fundamental para a sobrevida dos recém-nascidos, porém priorização das questões relacionadas às necessidades psicoafetivas dos bebês e de seus familiares não deve ser deixada de lado(17). 
A enfermagem e a família sempre estiveram próximas, vivendo momentos difíceis que demandam dela ações, sentimentos e pensamentos que, muitas vezes ultrapassam suas possibilidades conhecidas, a família necessita de um enfermeiro capaz, que the ajude a olhar esses momentos como possibilidade de superar-se nas habilidades que Ihe faltam para o enfrentamento da doença do bebê $\hat{e}^{(13)}$.

A equipe de enfermagem devido a sua disponibilidade, permanência, acessibilidade e à variedade de contexto nos quais encontram os pacientes, tem a oportunidade de aliviar o intenso estresse dos pais e a ansiedade associada à tragédia do evento ou da doença em si.

Salientando o papel da enfermagem na UTIN, ressaltamos que "a assistência e o cuidado de enfermagem devem ser considerados como a mola propulsora para humanizar o ambiente do CTI"(18).

A comunicação é necessária ao relacionamento interpessoal profissional de enfermagem/familiares. A equipe de enfermagem deve demonstrar sensibilidade à comunicação verbal e não-verbal, capacidade de ouvir atentamente, saber o que falar e quando falar e utilizar uma linguagem clara e acessível $^{(13)}$.

Além da linguagem apropriada para o nível de conhecimento dos pais, a equipe de enfermagem deve proporcionar aos pais ou a outros familiares, a oportunidade de visualizar e tocar a criança é extremamente útil ao desenvolvimento do apego e do vínculo afetivo após o nascimento.

Outro aspecto que deve ser levado em consideração pela equipe de enfermagem, diz respeito aos horários de visitas que são dispensados aos familiares, sendo estes, momentos em que o envolvimento dos pais e familiares com a equipe poderia ser intensificado no sentido de se promover o apego com a criança. Sem dúvida, esta é uma oportunidade de a enfermagem prestar-lhes informações, não apenas sobre o quadro clínico, mas sobre o funcionamento do setor, equipamentos, e, sobretudo, demonstrar interesse pela presença e pelos cuidados que podem ser prestados pelos familiares ao recém-nascido.

Durante este momento, a enfermagem pode acompanhar a duração do tempo que os pais visitam o bebê e como eles agem, como dirigem sua atenção, que comentários fazem durante a visita e que habilidades, mostram ter, que propicie um cuidado satisfatório ao seu filho. Neste período, também é oportuno propiciar informações à família, já que isto faz com que se possa identificar a percepção da família acerca da vida do seu familiar. O tempo dispensado para os pais ficarem com o filho pode ser desperdiçado se não houver alguém que oriente sobre sua conduta junto ao bebê, promovendo a formação e/ou manutenção do vínculo.

Percebemos que o relacionamento entre o profissional de enfermagem e a família deve ser um encontro de subjetividades do qual emergem novas compreensões e interpretações, contribuindo para o sucesso do tratamento e a superação da crise ocorrida durante a hospitalização do RN.

Nesse sentido, é importante estarmos atentos ao fato de que "as propostas de humanização em saúde também envolvem repensar o processo de formação do 
Reichert APS, Lins RNP, Collet N. Humanização do Cuidado da UTI Neonatal. Revista Eletrônica de Enfermagem [serial on line] 2007 Jan-Abr; 9(1): 200-213. Available from: URL: http://www.fen.ufg.br/revista/v9/n1/v9nla16.htm

profissional, ainda centrado, predominantemente, no aprendizado técnico e individualizado, com tentativas muitas vezes isoladas de exercício da crítica, criatividade e sensibilidade levando a cristalização dos sentimentos do profissional na construção de uma relação de ajuda eficiente aos usuários dos serviços de saúde bem como seus familiares" (19).

A literatura pesquisada aponta que humanizar a assistência à família e ao bebê implica oferecer um cuidado integral e singular a ambos, dando ênfase às suas crenças, valores, individualidades e personalidade, uma vez que cada ser é único, porém, envolvido em um contexto familiar, que possui uma história de vida, e por isso, deve ser respeitado para que se possa manter a dignidade desse grupo durante a hospitalização.

\section{CONSI DERAÇÕES FI NAIS}

Tendo em vista o objetivo delimitado no processo de realização desta pesquisa, a saber, identificar na literatura ações de enfermagem que contribuem para a humanização da assistência na Unidade de Terapia Intensiva Neonatal salientamos que a análise revelou que essas ações envolvem aspectos relacionados ao ambiente da UTIN, ao vínculo afetivo entre pais/família e filho tendo a enfermagem como agente facilitador no processo de humanização.

Este estudo apresenta aspectos que podem minimizar o estresse na UTIN como uma das formas de humanização do cuidado. Para tanto, acreditamos ser necessário extrapolar ações individuais para a busca da construção de processos coletivos envolvendo todos os agentes que participam da assistência. Isso implica em garantir uma equipe em número suficiente e capacitada tecnicamente para o consumo de tecnologias disponíveis para melhorar e prolongar a vida do RN, em criar ambientes de trabalho que promovam o relacionamento interpessoal, em humanizar as relações de trabalho, em promover ambiente seguro e confortável ao RN, família e equipe. Assim, os gestores dos serviços precisam estar sensibilizados para atender às demandas específicas desse setor no hospital.

A humanização da assistência na UTIN deve se pautar no cuidado singular, na integralidade e no respeito à vida. É dependente do encontro envolvendo cuidador e ser cuidado. A construção da "integralidade não deve ser transformada em um conceito, mas sim numa prática do cuidado que trata da valorização da vida, do respeito ao outro e das diferenças entre os seres humanos"(20). Portanto, momentos de reflexão acerca do processo de trabalho no cotidiano são fundamentais a fim de se rever as práticas.

A humanização do cuidado aparece relacionada a atitudes de dar atenção, ter responsabilidade, cuidar bem, respeitando as particularidades de cada um, e principalmente promovendo uma assistência integral ao bebê e família. De acordo com os profissionais, ação humanitária relaciona-se com a maneira como se cuida.

O cuidado com a manipulação, postura, som, luz, estresse e dor, à luz do conhecimento das capacidades do recémnascido, não podem deixar de ser considerados pela equipe. Esta atitude, em muito enriquecerá a equipe de saúde, em especial a enfermagem, uma vez que novos alicerces 
serão construídos, com mudanças de paradigmas para uma nova prática.

Apesar do grande esforço que os profissionais de enfermagem possam estar realizando no sentido de humanizar o cuidado em UTIN, esta é uma tarefa difícil, pois demanda atitudes às vezes individuais contra todo um sistema tecnológico dominante. E, muitas vezes, a própria dinâmica do trabalho em uma UTI não possibilita momentos de reflexão acerca do seu do seu processo de trabalho.

A presença efetiva da equipe de enfermagem com escuta sensível é tão importante quanto o procedimento técnico, uma vez que nem sempre os conhecimentos técnicos funcionam tão bem diante das situações de estresse. Somente vendo, escutando e sentindo o recém-nascido e a família como um todo, estaremos atendendo e compreendendo a essência do cuidar humano.

É oportuno destacar a responsabilidade que a enfermagem possui de envolver os familiares, centrado na figura dos pais, no cuidado direto aos seus bebês. Métodos e intervenções devem ser implementados, com a finalidade de propiciar a participação dos mesmos no cuidado de tais crianças, com o auxílio de procedimentos estritamente necessários a sua evolução, minimizando condutas agressivas e estressantes.

\section{REFERÊNCIAS}

1. Oliveira ME. Cuidando-aprendendo enfermagem com amor: uma experiência dialógica com mães/recém-nascidos pré-termo. [Mestrado]. Florianópolis (SC): Programa de Pós-Graduação em Enfermagem/UFSC; 1998.

2. Carvalho RA. Cuidado-presença: importância na atenção ao recém-nascido de alto risco. Passo Fundo (RS): Editora da UPF; 2001.
3. Moreira MEA. Estressores em mães de recém-nascidos de alto risco: sistematização da assistência de enfermagem. [Mestrado]. J oão Pessoa (PB): Programa de Pós-Graduação em Enfermagem/UFPB; 2001.

4. Minayo MCS. O desafio do conhecimento: pesquisa qualitativa em saúde. 9a ed. São Paulo (SP)/Rio de Janeiro (RJ): Hucitec/Abrasco; 2006.

5. Gil AC. Métodos e técnicas de pesquisa social. 5a ed. São Paulo (SP): Atlas; 1999.

6. Moreira MEL, Rodrigues MA, Braga NA, Morsch DS. Conhecendo uma UTI Neonatal, In: Moreira MEL, Braga NA, Morsch DS. (Orgs). Quando a vida começa diferente: o bebê e sua família na UTI neonatal. Rio de Janeiro (RJ): Fiocruz; 2003, p. 29.

7. Reichert APS, Costa SFG. Experiência de ser mãe de recém-nascido prematuro. João Pessoa (PB): Idéia; 2000.

8. Nogueira RP. O trabalho em serviços de saúde. In. Santana JP. (org.) Desenvolvimento gerencial de unidades básicas do Sistema Único de Saúde (SUS). Brasília (DF): OPAS; 1997.

9. Ratto KMN. É possível humanizar a assistência ao parto? Avaliação de dois nos da maternidade Leila Diniz. Saúde em Foco 2001 jul; n.21: 115-135.

10. Lima GC Humanização em unidade de terapia intensiva pediátrica: discurso de enfermeiras. [Especialização]. João Pessoa (PB): Centro de Ciências da Saúde/UFPB; 2004.

11. Lamego DTC, Deslandes SF, Moreira MEL. Desafios para a humanização do cuidado em uma unidade de terapia intensiva neonatal cirúrgica. Revista de Ciências e Saúde Coletiva 2005; 10 (3): 669-675. Disponível em: http://www. scielo.br/pdf/csc/v10n3/a23v10n3. pdf.

12. Ferraz MA, Chaves RL. Bebês prematuros: aspectos emocionais. Pediatria Moderna 1996 dez; 30 (7): 784-790.

13. Lamy ZCP, Gomes R, Carvalho M. A percepção de pais sobre a internação de seus filhos em unidade de terapia intensiva neonatal. Jornal de Pediatria 1997; 73 (5): 293-297.

14. Scochi CGS et al. Cuidado individualizado ao pequeno prematuro: o ambiente sensorial em unidade de terapia intensiva neonatal. Revista Paulista de Enfermagem 2001 jan/abr; 14 (1): 9-16.

15. Nascimento ERP, Martins JJ. Reflexões acerca do trabalho da enfermagem em UTI e a relação deste com o indivíduo hospitalizado e sua família. Nursing Revista Técnica de Enfermagem 2000 out; 3 (29): 26-30. 
16. Rossato-Abéde LM, Angelo M. Crenças determinantes na interação da enfermeira acerca da presença dos pais em unidades neonatais de alto risco. Revista LatinoAmericana de Enfermagem 2002 jan/fev; 10 (1): 48-54.

17. Carvalho RMA de. A enfermagem na promoção da presença dos pais-familiares em CTI pediátrica/neonatal. Revista Médica do Hospital São Vicente de Paulo 2002 jul/dez; 14 (31): 32-34.

18. Araújo $A D$ et al. Trabalho no centro de terapia intensiva: perspectivas da equipe de enfermagem. REME - Revista Mineira de Enfermagem 2005 jan/mar; 9 (1): 20-28.

19. Fernandes CNS, Andraus LMS, Munari DB. O aprendizado do cuidar da família da criança hospitalizada por meio de atividades grupais. Revista Eletrônica de Enfermagem [serial on line] 2006. [cited 2006 jan 11] 8(01): 108$118 . \quad$ Availablem from: http://www.fen.ufg.br/revista/revista8_1/origi nal 14.htm.

20. Pinho IC, Siqueira JCBA, Pinho LMO. As percepções do enfermeiro acerca da integralidade da assistência. Revista Eletrônica de Enfermagem [serial on line] 2006. [cited 2006 jan 11] 8 (1): 42-51.Available from: http://www. fen.ufg.br/revista/revista8 1/origi nal_05.htm.

Artigo recebido em 13.12.06

Aprovado para publicação em 30.04.07 